\title{
A Study on the Awareness and Utilization of Pap Smear Among Female Health Workers in a Tertiary Hospital in Nigeria
}

\section{Omonua $\mathrm{KI}$, Isah $\mathrm{AD}^{\star}$ and Agida ET}

Department of Obstetrics and Gynaecology, College of Health Sciences, University of Abuja, Abuja, Nigeria

*Corresponding author: Isah DA, Department of Obstetrics and Gynaecology, College of Health Sciences, University of Abuja, Abuja, Nigeria, Tel: +2348061109664; Email: denisanthonyisah@yahoo.com

Received date: February 9, 2019; Accepted date: February 22, 2019; Published date: February 27, 2019

Copyright: ( 2019 Omonua KI, et al. This is an open-access article distributed under the terms of the Creative Commons Attribution License, which permits unrestricted use, distribution, and reproduction in any medium, provided the original author and source are credited.

\begin{abstract}
The study was a descriptive cross-sectional survey using self-administered questionnaires on female doctors, nurses and pharmacists in University of Abuja Teaching Hospital, Gwagwalada, Abuja. Knowledge about cervical cancer and practices regarding Pap smear as a screening method was tested.

The results obtained showed that $13 \%$ of the respondents had their sexual debut (coitarche) before the age of 20 years and $35.5 \%$ of them had multiple sexual partners. (90\%) were aware of the disease, cervical cancer and most $(90 \%)$ knew the symptoms and signs of cervical cancer and also ways of preventing it. However, $58 \%$ had adequate knowledge of the risk factors for cervical cancer. $97.5 \%$ of the female health workers were aware of the Pap smear as a screening test for cervical cancer but most of them $(76.5 \%)$ had never done it before. The medical doctors showed the highest level of awareness about Pap test (100\%) and the least aware were the pharmacists $(71.4 \%)$. When contrasted, Pap smear awareness and utilization, there was no correlation between Pap test utilization and Pap smear awareness (Pearson's correlation $0.96, \mathrm{P}<0.05$ ) as only $24.1 \%$ of people who were aware had done a pap smear test. There were multiple reasons given by respondents for not having had a Pap test. The majority, $(40 \%)$ had no reason and $(30.9 \%)$ had not thought about it. The medical literature and seminars were the most cited sources of information about Pap smear. Medical doctors were the commonest source of information for the doctors while the nurses got their information mostly from medical literature and seminars. The majority (72.1\%) of the respondents suggested that more education at the place of work would help improve the knowledge on cervical cancer and $32 \%$ suggested the use of mass media in addition so as to impact both themselves and women in the society. On measures that would help increase participation, $40.5 \%$ suggested that the pap smear test be offered at no cost.
\end{abstract}

Keywords: Pap smear; Utilization; Awareness; Health worker

\section{Introduction}

Globally, cervical cancer is second to the breast cancer as the commonest female cancer [1]. In the year 2000, there were over 471,000 new cases diagnosed and 280,000 deaths from cervical cancer worldwide, with the vast majority $(80 \%)$ occurring in developing countries[2,3].

Cervical cancer is a deadly disease even in developed countries. Of the estimated 10,000 women who are diagnosed with cancer annually in the United States, 3900 die from the disease [4]. In developing countries, cervical cancer is the leading female malignancy. It is the most common cancer among women in sub-Saharan Africa and has significant morbidity and mortality when detected at an advanced stage. Conversely, early identification of the disease can lead to a cure rate as high as $85 \%$ [5]. In Nigeria today, cervical cancer remains the most common malignancy of the reproductive tract. An incidence of $66.2 \%, 63.1 \%, 63.7 \%$ and $62.3 \%$ [6-9] was reported in Zaria, Ilorin, Benin and PortHarcourt respectively. With these figures and given a population of 32 million women in Nigeria, we would expect to treat approximately 8000 new cases of invasive cervical cancer annually [6].

The incidence of cancer and deaths from invasive cervical cancer has decreased by nearly $70 \%$ in the USA and other developed countries in the past 50 years. This is following the introduction of screening programmes [10] as studies have shown sensitivity and specificity of Pap smear screening to be $50-75 \%$ and $98-99 \%$ respectively [2]. However, even with widespread screening, cervical cancer remains the third most common gynecologic malignancy in the USA, and the most common cause of mortality from a gynecologic malignancy worldwide as the numbers of deaths each year from this disease remain at around 4000 despite the large increase in the incidence of pre-invasive disease, concurrent with the increase in the number of sexual partners and earlier age of onset of intercourse. Unfortunately, approximately $50 \%$ of women who are diagnosed with and die from cervical cancer have never had cytologic screening, nor have been inadequately screened. Another 10\% have not been screened in the past 5 years [1].

The burden of cervical cancer is potentially large in sub-Saharan Africa and there is an urgency to make it a public health priority. The development of systematic cytological smear screening programmes has not been possible in most low resource settings including Nigeria however, the availability of low-cost cervical screening technologies of HPV testing and visual inspection methods and HPV vaccines represent tools that provide realistic opportunities for cervical cancer prevention in sub-Saharan Africa. In order to successfully introduce, implement and sustain a prevention programme, good data from across multi-disciplines dedicated to the prevention of cervical cancer are needed $[11,12]$. 
Page 2 of 9

The magnitude of the problem has been under recognized and under prioritized compared to competing health priorities such as HIV/AIDS, Tuberculosis and malaria. This is due to lack of epidemiological data and poor awareness, lack of human and financial resources, nonexistent cancer service policies and lack of political selfwill to address the complex problem [12]. The only available activity has been to use opportunistic screening of those women who come to the health units for other reasons and screening of these women then becomes the responsibility of the medical worker who should know those eligible.

There are substantial health benefits for early cancer detection, but many women with access do not get screened. This may be due to many known sociocultural barriers to cancer screening, for example, lower socioeconomic status, race and lack of health insurance, access to care and education. Others are lack of awareness of symptoms and signs of early stages of cervical cancer, inappropriate beliefs and misconception, and perceived non-susceptibility [1]. According to the American cancer society, among women with insurance, $18 \%$ had not had a cervical smear test in the previous three years [13]. Even in the United Kingdom where there is universal health coverage, a substantial percentage still do not obtain routine screening [14].

The level of awareness and utilization of cervical cytology services among women in Nigeria is unclear as there is no reliable populationbased cancer registry or preventive programme database and very few regional based studies have been reported in the country [15]. Reports of some studies show that less than $10 \%$ of women in Maiduguri are aware of cervical cancer and its symptom 15, there's inadequate knowledge of aetiology and prevention of cervical cancer among nurses in Ibadan [16] and there's 52.8\% awareness of cervical cancer screening methods among women in Owerri [17].

This then implies that although increased awareness of health issues by the population should encourage the use of disease prevention measures, it may not be essentially true for cervical cancer screening in Nigeria using the Pap smear. Improved awareness of Pap test by Nigerian women may not necessarily increase its use. This was also tested and shown in studies carried out on female medical practitioners who were expected to be advocates of disease screening and therefore lead by example. In Enugu state, Nigeria only $18 \%$ of these women had done the Pap smear even though they were all aware of it [18].

This hospital is a major training institution for medical workers and therefore should be the pace setter for best practices regarding cervical cancer prevention and management as many cancer patients are referred here for treatment. The aim of this study therefore is to appraise the level of awareness and utilization of Papanicolaou (Pap) smear for cervical cancer screening among the female health workers at the University of Abuja Teaching Hospital, Abuja.

The findings of this study will help to increase the awareness of cervical cancer among female health workers and thus encourage their use of disease-prevention measures. This would in turn make them create better awareness in the female population in the community and it would go a long way in reducing morbidity and mortality caused by cervical cancer in the nation. Also, it will help contribute to providing information for a national database with a view to establishing a meaningful prevention program in the country.

\section{Materials and Methods}

The study was a descriptive cross-sectional survey using pre-tested questionnaires on female health workers in University of Abuja Teaching Hospital, Gwagwalada, Abuja. The study was conducted at the University of Abuja Teaching Hospital, Gwagwalada. The hospital is a 350 bed Federal government owned tertiary institution situated in Gwagwalada, a high population density area in Abuja, Nigeria's Federal capital territory. It provides health care services to the inhabitants of Abuja and neighbouring states including Niger, Kaduna, Kogi and Nassarawa States. There are about 390 female health workers working in all the departments, comprising of all the female doctors, nurses/ midwives and pharmacists.

The sample size was calculated using the formulae: $n=Z^{2} p q / d^{2}$ where,

$\mathrm{n}=$ minimum sample size

$\mathrm{Z}=$ standard at 1.96

$\mathrm{p}=$ pap test utilization rate ( $14.1 \%$ in a study done in Benin)

$\mathrm{q}=1-\mathrm{p}$

$\mathrm{d}=$ precision at 0.05

Then, $\mathrm{n}=1.96 \times 1.96 \times 0.141 \times 0.859 / 0.05 \times 0.05$

$\mathrm{n}=186$.

Thus, the minimum sample size for this study is 186 . Also adding a $20 \%$ attrition or non-response rate, the minimum sample size of 223 was used.

The simple random sampling technique was employed in getting the participants. Participants answered a self-administered questionnaire (see attached copy) which was self-designed and contained both closed and open-ended questions that covered the following aspects: sociodemographic data, risk factors, knowledge of cervical cancer, knowledge of Pap smear as a screening method for cervical cancer and use of pap smear as a screening method for cervical cancer. Confidentiality was ensured to all respondents.

The consent of each participant and formal approval from the ethics and research committee of UATH were obtained.

\section{Data management}

The level of awareness (knowledge) about cervical cancer risk factors and Pap smear test was scored based on the number of correctly answered questions. A respondent with a score of 3 or greater was graded to be aware or else unaware. Information extracted was coded and analyzed using SPSS version 13, statistical package. Data were analyzed to identify relationships by Chi-square test. Test of significance was based on $95 \%$ confidence interval and $\mathrm{P}$ value of $<0.05$.

\section{Results}

Of the 223 questionnaires distributed, 200 questionnaires were returned and analysed, giving a response rate of $89.7 \%$. 
Citation: Omonua KI, Isah AD, Agida ET (2019) A Study on the Awareness and Utilization of Pap Smear Among Female Health Workers in a Tertiary Hospital in Nigeria. J Cytol Histol 10: 531. doi:10.4172/2157-7099.1000531

Page 3 of 9

\begin{tabular}{|l|l|l|}
\hline & Frequency & Percent \\
\hline Doctor & 44 & 22.0 \\
\hline Pharmacist & 7 & 3.5 \\
\hline Nurse/midwife & 149 & 74.5 \\
\hline Total & 200 & 100.0 \\
\hline
\end{tabular}

Table 1: Distribution of Cadre of respondents.

\begin{tabular}{|l|l|l|}
\hline Age distribution & Frequency & Percent \\
\hline $20-29$ & 40 & 20.0 \\
\hline $30-39$ & 75 & 37.5 \\
\hline $40-49$ & 68 & 34.0 \\
\hline$\geq 50$ & 200 & 8.5 \\
\hline Total & 17 & 100.0 \\
\hline
\end{tabular}

Table 2: Age distribution of respondents.

The age of the respondents ranged from $24-54$ years with a mean of $35.4 \pm 7.9$ years. The highest incidence was in the 30 - 39 year age group $75(37.5 \%)$ followed by the $40-49$ year age group with $68(34 \%)$. The

least number of participants were in the group $\geq 50$ years $(8.5 \%)$ (Tables 1-5).

\begin{tabular}{|l|l|l|}
\hline Marital status & Frequency & Percent \\
\hline Single & 44 & 22.0 \\
\hline Married & 145 & 72.5 \\
\hline Divorced/separated & 7 & 3.5 \\
\hline Widowed & 4 & 2.0 \\
\hline Total & 200 & 100.0 \\
\hline
\end{tabular}

Table 3: Marital status of respondents.

\begin{tabular}{|c|c|c|c|c|c|}
\hline & & Cadre & & & Total \\
\hline & & Doctor & Pharmacist & Nurse/midwife & Total \\
\hline Age & $20-29$ & 31 & 2 & 7 & 40 \\
\hline & $30-39$ & 11 & 4 & 60 & 75 \\
\hline & $40-49$ & 0 & 1 & 67 & 68 \\
\hline & $\geq 50$ & 2 & 0 & 15 & 17 \\
\hline Total & & 44 & 7 & 149 & 200 \\
\hline
\end{tabular}

Table 4: Age vs. Cadre cross tabulation.

The age distribution cross-tabulated by the cadre of respondents shows that majority of the Nurses were in an older age group (40-49 years) compared to the doctors who were mostly in the age group
20-29 years. $88.2 \%$ of the respondents above 50 years of age were nurses. 
Citation: Omonua KI, Isah AD, Agida ET (2019) A Study on the Awareness and Utilization of Pap Smear Among Female Health Workers in a Tertiary Hospital in Nigeria. J Cytol Histol 10: 531. doi:10.4172/2157-7099.1000531

Page 4 of 9

\begin{tabular}{|l|l|l|}
\hline Coitarche & Frequency & Percent \\
\hline$<20$ & 26 & 13.0 \\
\hline $20-24$ & 84 & 42.0 \\
\hline $25-29$ & 65 & 32.5 \\
\hline$\geq 30$ & 18 & 9.0 \\
\hline Nil & 7 & 3.5 \\
\hline Total & 200 & 100.0 \\
\hline
\end{tabular}

Table 5: Age at first intercourse (coitarche).

A minority, $26(13 \%)$ of the respondents, had their sexual debut (coitarche) before the age of 20 years. 7 (3.5\%) of the respondents have had no sexual experience (Table 6).

\begin{tabular}{|l|l|l|}
\hline Number of Sex partners & Frequency & Percent \\
\hline 1 & 122 & 61.0 \\
\hline 2 & 47 & 23.5 \\
\hline 3 & 9 & 4.5 \\
\hline 4 & 6 & 3.0 \\
\hline$\geq 5$ & 9 & 4.5 \\
\hline Nil & 7 & 3.5 \\
\hline Total & 200 & 100.0 \\
\hline
\end{tabular}

Table 6: Total number of sexual partners (both past and present).

$71(35.5 \%)$ of the respondents have had multiple sexual partners. The modal number of sexual partners was 1 , with a range of 0-6. 7 respondents have never had any sexual experience.

A large number of the female health workers 180/200 (90\%) were aware of the disease, cervical cancer. A similar number 195/200

\begin{tabular}{|l|l|}
\hline Knowledge & \% with good knowledge \\
\hline Risk factors for cervical cancer & $58 \%$ \\
\hline Symptoms and signs of cervical cancer & $90 \%$ \\
\hline Ways of preventing cervical cancer & $95.50 \%$ \\
\hline
\end{tabular}

Table 7: Knowledge about cervical cancer.

Most participants knew the symptoms and signs of cervical cancer and also ways of preventing it. However, only $58 \%$ had adequate knowledge of the risk factors for cervical cancer (Table 7).

(97.5\%) were aware of the Pap smear as a screening test for cervical cancer. There was complete lack of awareness and utilization of Pap test among the seven respondents who have had no sexual experience.

\begin{tabular}{|l|l|l|}
\hline & Frequency & Percent \\
\hline Use of Pap smear & & \\
\hline
\end{tabular}


Citation: Omonua KI, Isah AD, Agida ET (2019) A Study on the Awareness and Utilization of Pap Smear Among Female Health Workers in a Tertiary Hospital in Nigeria. J Cytol Histol 10: 531. doi:10.4172/2157-7099.1000531

Page 5 of 9

\begin{tabular}{|c|c|c|}
\hline Detection of sexually transmitted diseases & 7 & 3.5 \\
\hline Detection of human papillomavirus infection & 49 & 24.5 \\
\hline Detection of precancerous state of cervical cancer & 116 & 58 \\
\hline Cure of cervical cancer & 16 & 8 \\
\hline Prevention of cervical cancer & 7 & 3.5 \\
\hline Do not know & 5 & 2.5 \\
\hline Total & 200 & 100 \\
\hline \multicolumn{3}{|l|}{ Recommended freq. of a Pap smear test } \\
\hline \multicolumn{3}{|l|}{ Annually } \\
\hline Every $3-5$ years & 100 & 50 \\
\hline At least once in 10 years & 58 & 29 \\
\hline Do not know & 5 & 2.5 \\
\hline Total & 37 & 18 \\
\hline Meaning of positive Pap smear result & 200 & 100 \\
\hline \multicolumn{3}{|l|}{ Full-blown cancer of cervix } \\
\hline Cervical cancer that is about to start & 25 & 12.5 \\
\hline Cancer of the breast & 125 & 62.7 \\
\hline \multicolumn{3}{|l|}{ Infection } \\
\hline Other & - & - \\
\hline I do not know & 13 & 6.4 \\
\hline Total & 2 & 1 \\
\hline Who should have Pap smear done & 35 & 17.2 \\
\hline Women of all age & 200 & 100 \\
\hline \multicolumn{3}{|l|}{ Women that are still giving birth } \\
\hline Women that are 18 years and above & 40 & 20 \\
\hline Women above 65 years of age & 25 & 12.5 \\
\hline Do not know & 113 & 56.5 \\
\hline \multirow[t]{3}{*}{ Total } & - & - \\
\hline & 22 & 11 \\
\hline & 200 & 100 \\
\hline
\end{tabular}

Table 8: Knowledge of Pap smear.

\begin{tabular}{|l|l|l|l|l|}
\hline \multicolumn{2}{|c|}{} & \multicolumn{2}{l|}{ Heard of pap smear } & Total (100) \\
\cline { 3 - 5 } \multicolumn{2}{|c|}{} & Yes (\%) & No (\%) & \multirow{2}{*}{$4(100)$} \\
\hline Cadre & Doctor & $44(100)$ & $0(0)$ & $7(100)$ \\
\cline { 2 - 4 } & Pharm & $5(71.4)$ & $2(28.6)$ & 74 \\
\hline
\end{tabular}


Citation: Omonua KI, Isah AD, Agida ET (2019) A Study on the Awareness and Utilization of Pap Smear Among Female Health Workers in a Tertiary Hospital in Nigeria. J Cytol Histol 10: 531. doi:10.4172/2157-7099.1000531

Page 6 of 9

\begin{tabular}{|l|l|l|l|l|}
\hline & Nurse & $145(97.3)$ & $4(0.7)$ & $149(100)$ \\
\hline Total & $195(97.5)$ & $5(2.5)$ & $200(100)$ \\
\hline
\end{tabular}

Table 9: Knowledge of Pap smear vs. Cadre.

Below tables show Pap test awareness by female health workers in UATH stratified according the category of the workers. The medical doctors showed the highest level of awareness about Pap test (100\%) and the least aware were the pharmacists (71.4\%). Further statistical analysis showed that there was significantly no correlation between the Pap test awareness and the different category of female health workers (Pearson's correlation, 20.19, P, 0.05) (Tables 8-10).

\begin{tabular}{|l|l|l|}
\hline Source of information & Frequency & Percent \\
\hline Medical doctors & 27 & 13.5 \\
\hline Nurses & 15 & 7.5 \\
\hline Medical literature & 80 & 40.0 \\
\hline Seminars/CME & 60 & 30.0 \\
\hline Friends/relatives & - & - \\
\hline TV/Radio & 16 & $8 . .0$ \\
\hline Others & 2 & 1.0 \\
\hline Total & 200 & 100.0 \\
\hline
\end{tabular}

Table 10: Source of information about Pap smear.

\begin{tabular}{|l|l|l|l|l|l|l|l|}
\hline & Med. Doctor & Nurses & Med, Literature & Seminars/CME & $\begin{array}{l}\text { Friends/ } \\
\text { relatives }\end{array}$ & TV/Radio \\
\hline Doctor & 15 & 0 & 0 & 22 & 7 & - & 0 \\
\hline Pharm & 0 & 15 & 53 & 0 & - & - & 2 \\
\hline Nurse & 13 & 15 & 80 & 63 & - & 13 \\
\hline Total & 28 & & & 200 & -2 \\
\hline
\end{tabular}

Table 11: Cadre vs. Source of information Cross tabulation.

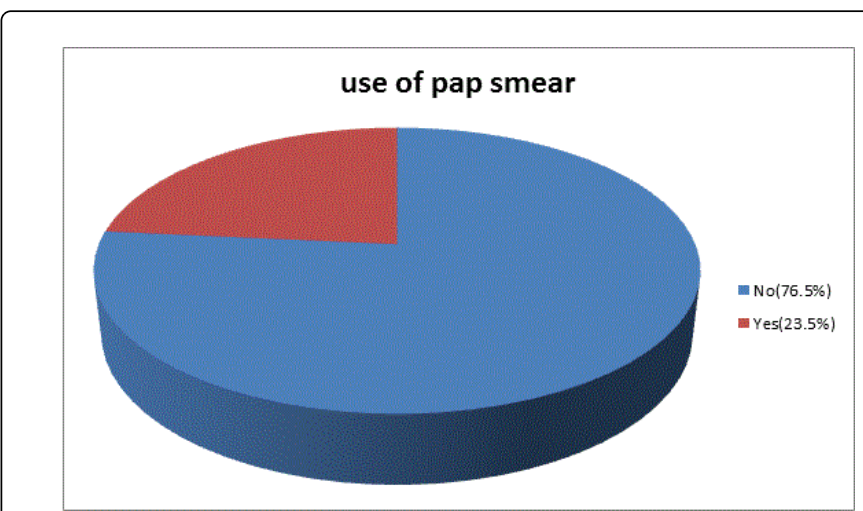

Figure 1: Use of Pap smear.
The sources where respondents obtained information about Pap test are shown in Table 11. For the different categories of health workers in the study, the medical literature and seminars were the most cited sources of information about Pap smear. Friends or relatives were not mentioned as a source of information. Medical doctors were the commonest source of information for the doctors while the nurses got their information mostly from medical literature and seminars.

A minority of the female health workers $47 / 200$ (23.5\%) have had a Pap test (Figure 1). Among respondents who have had Pap smear, a large proportion was nurses $95.7 \%$ compared with $4.3 \%$ and $0.0 \%$ among the doctors and pharmacists respectively. There was a significant variation in utilization of Pap test across the various categories of the female health workers (Pearson Chi-square 8.4, P, 0.05; likelihood ratio Chi-square 11.4, P, 0.05) (Table 12). 


\begin{tabular}{|l|l|l|l|l|}
\hline \multicolumn{2}{|c|}{} & \multicolumn{2}{l|}{ Use of pap smear } & \multirow{2}{*}{ Total (\%) } \\
\cline { 2 - 5 } \multicolumn{2}{|c|}{} & YES (\%) & NO (\%) & \multirow{2}{*}{$44(22.0)$} \\
\hline \multirow{3}{*}{ Cadre } & Doctor & $2(4.3)$ & $42(27.5)$ & $7(3.5)$ \\
\cline { 2 - 5 } & Pharm & $0(0)$ & $7(4.6)$ & $149(74.5)$ \\
\cline { 2 - 5 } & Nurse & $45(95.7)$ & $104(68.0)$ & $200(100)$ \\
\hline Total & $47(100)$ & $153(100)$ & $200)$ \\
\hline
\end{tabular}

Table 12: Use of pap smear vs. Cadre.

When contrasting Pap smear awareness and utilization, there was no correlation between Pap test utilization and Pap smear awareness
(Pearson's correlation $0.96, \mathrm{P}, 0.05$ ) as only $24.1 \%$ of people who were aware had done a pap smear test (Table 13).

\begin{tabular}{|l|l|l|l|l|}
\hline \multicolumn{2}{|c|}{} & Use of pap smear & Total \\
\cline { 2 - 5 } \multicolumn{2}{|c|}{} & YES & NO & \\
\hline Aware of pap smear & YES & 47 & 148 & 195 \\
\cline { 2 - 6 } & NO & 0 & 5 & 5 \\
\hline Total & 47 & 153 & 200 \\
\hline
\end{tabular}

Table 13: Pap smear awareness vs. Utilization.

There were multiple reasons given by respondents for not having had a Pap test. The majority, 80/200 (40\%) had no reason and 40/200 (30.9\%) had not thought about it. 7 (3.6\%) believed that they were not at risk of developing cervical cancer while $16(8.2 \%)$ were too busy to screen.

One hundred and thirty-three 66.4\%) had referred a patient for a Pap smear test and of those who have not done so, $67.5 \%$ had no reason why while $19.5 \%$ felt it was strictly the job of the gynaecologist.

A multivariate analysis for factors that could influence the level of knowledge of Pap smear and its use found a negative relationship between uptake of pap smear and the cadre of respondents and number of sexual partners. However, knowledge of Pap smear was positively influenced by the cadre, age and number of sexual partners. There was a negative correlation with coitarche but knowledge of pap smear did not influence uptake of pap smear.

The majority $(72.1 \%)$ of the respondents suggested that more education at the place of work would help improve the knowledge on cervical cancer and 32\%\% suggested the use of mass media in addition so as to impact both themselves and women in the society. On measures that would help increase participation, $40.5 \%$ suggested that the pap smear test be offered at no cost.

\section{Discussion and Conclusion}

Cancer of the cervix is a preventable disease, and a key aspect of its prevention is the detection of the premalignant form by cervical screening.

The major finding in this study data was that Pap test utilization among the female health workers was (23.5\%). Even though this result is low, it is significantly higher than that of earlier studies done in Nigeria $[1,10,18,19]$ and in other developing countries [20,21]. In contrast, a study done in a University teaching hospital in Thailand found that $56.4 \%$ of the nurses had had a Pap smear test regularly and $86.5 \%$ intended to check regularly in the future [22]. These differences may have been due to differences in professional groups included in the various studies with consequent variation in their sociodemographic characteristics which may have impacted on their attitude to the use of Pap smear.

Despite this low figure, the study in contrast has shown that the health workers have a very good knowledge of the symptoms and signs of cervical cancer (90\%) and an average knowledge about Pap smear. This is indicated by the $58 \%$ respondents who knew that the pap test was used to detect precancerous states and the $62.7 \%$ who knew that a positive smear might mean a cervical cancer that is about to start. In the study among female doctors in Enugu [18] where uptake of Pap smear was $18 \%$, knowledge about Pap smear was much higher (as expected), up to a hundred percent was recorded. These figures show that there is a wide gap between personal knowledge and uptake of Pap test. Many studies have shown that cervical cancer and Pap testing awareness positively influence the utilization of cervical cancer screening services $[7,23]$ but it was not so in this study. This was unexpected as we hold this population of women to be better informed about the risk factors of developing cervical cancer.

Lack of an organized screening program, suboptimal level of awareness, and misconceptions in the cause of cervical cancer and use of Pap smear are some of the identified factors for the low Pap test uptake among women in this study. Even so, on the basis of the study result, the extent a woman is informed did not contribute to her Pap smear service uptake. This was demonstrated by the negative correlation between the Pap test awareness and the different categories of female health workers. 
Culturally, women hardly reveal personal medical details especially in a polygamous setting were perceived personal risks are blamed on third party 1 and reports from other centers in Nigeria and other parts of Africa reveal that superstition and inappropriate belief are the commonest excuse for not having had a Pap test [7,24].

In developed countries with market economies like UK, with computerized national screening program, over $85 \%$ of their target population have benefited from Pap testing. Existing population-based screening program, educational level, women empowerment, and adequate mass media campaign are some of the offered explanations for these observed wide differences in the various studies [1].

An analysis of factors that could influence the health workers awareness and utilization of Pap test found a relationship between knowledge of Pap smear and cadre, age and number of sexual partners. There was a negative correlation between uptake and number of sexual partners in this study as a significant number out of $39.1 \%$ of the female health workers who had multiple sexual partners (some up to five partners) and were aware of this as a risk factor for cervical cancer either had no reason for screening or had not thought about it. This finding is similar to that seen in Benin1 where $59.9 \%$ of the respondents had multiple sexual partners but did not think they were at risk despite their good knowledge of the risk factors for the disease. This aberration in behavior explicitly calls for appropriate interventions to improve accurate perception that could translate to an appropriate behavioral change by the health care providers, which will be beneficial to the community.

A large proportion of the nurses (36.6\%) had inadequate knowledge of risk factors for cervical cancer. This is similar to the findings in Uganda [20], but contrasts to findings by Tessaro, et al. in the United States in a study on nurse practitioners who knew most of the risk factors such as multiple sexual partners, history of HPV infection and sexual intercourse at an early age. All of the pharmacists also had inadequate knowledge of the risk factors in contrast to the doctors of whom $95 \%$ had adequate knowledge of the risk factors. This could be explained by the level of education of these nurses, most of whom have diplomas and certificates in nursing and the pharmacists who have little or no clinical knowledge and experience as compared to the medical doctors. This fact can be further strengthened by the fact that $71 \%$ of the nurses got their information either from medical literature or from seminars. There was no mention of the nursing school as a source. However, these finding contrasts that found in a study done in Tanzania [21] where nursing school was a major source of information but despite this, knowledge off cervical cancer and screening was poor and reflects the inadequacy of the information given in nursing school. In the same vain, all the pharmacists got their information either from medical literature or the media.

The medical doctors were expectedly more informed among the categories of female health workers, but the nurses' uptake of services was higher. This may be due to the fact that a significant number of nurses were in an older age group but on the other hand, accurate knowledge of the risk factors for cervical cancer as seen among the doctors may not be a guarantee for screening service uptake. This was also the case in the study done in Enugu [22]. It may inadvertently work against service uptake.

It is discouraging that only a minority of the workers in this study received their information from medical doctors and nurses alone. Health care providers play a significant role in dissemination of medical information in the community, therefore targeting this group to improve their utilization of cytology services will undoubtedly have a beneficial effect on Pap test uptake rate in any future planned national cancer screening program.

On the reason for not participating in the screening programme, $40 \%$ said there was no reason and $29.9 \%$ had not even thought about it. Other reasons were lack of symptoms and their being too scared of the outcome. In Uganda, Mutyaba, et al. found that the respondents' reasons for not being screened were not feeling at risk, lack of symptoms, carelessness, fear of vaginal examination, lack of interest, test being unpleasant and not yet being of risky age [20]. Gharoro, et al. show that the majority $(89.2 \%)$ of those who had never had a Pap test did not feel at risk of developing cervical cancer [1].

In departments other than Gynaecology, the negative practice (by both doctors and nurses) of not screening the patients who came under their care could be attributed to their routines, but this would not explain the reluctance to get screened themselves despite the availability of a service almost any time they wished to. This study showed that $33.6 \%$ of respondents had not referred any patient for a pap test and majority of these did not have any reason for their attitude. $6.4 \%$ felt it was strictly the job of the gynaecologist. However, Studies have shown it is possible to train midwives/nurses to screen for cervical [20]. Attitudes that it is for doctors or gynaecologists need to change.

Overall, the study results indicated a big gap regarding cervical cancer screening in UATH. To reduce the incidence of and death from invasive cervical cancer, the attitudes and practices of the health care providers need to be changed and in the opportunistic screening system, the onus is on the health worker who handles the eligible women to offer screening or refer her to a unit where screening could be done. In UATH, Pap smear is exclusively performed in the gynaecological department and women from other units should be referred to the gynaecological unit for screening.

\section{Recommendations}

There is need for a re-sensitization of health workers about cervical cancer and importance of screening through organization of seminars and workshops and the use of medical literature in the form of bulletins and fliers.

Training curricula of nurses and medical students need to be revised to include more practical cervical cancer screening skills.

For opportunistic screening to work, health workers in other departments need to be sensitized on the gravity of cervical cancer and to remember to refer all eligible women who come into their care for screening. Routine cervical cancer counselling and screening with optout option should therefore be offered to every eligible woman attending the outpatient clinic.

Special attention should be paid to availability of screening services in the general hospitals and possibly the primary healthcare centers.

The government should be sensitized about the burden of the disease so that they will see the need to put in place the necessary infrastructure needed to establish a successful national screening programme.

The government should also look into the possibility of making the screening free of charge (as in the case of HIV screening). This would encourage more participation in the screening programme. 
Citation: Omonua KI, Isah AD, Agida ET (2019) A Study on the Awareness and Utilization of Pap Smear Among Female Health Workers in a Tertiary Hospital in Nigeria. J Cytol Histol 10: 531. doi:10.4172/2157-7099.1000531

Page 9 of 9

\section{References}

1. Gharoro EP, Ikeanyi EN (2006) An appraisal of the level of awareness and utilization of the pap smear as a cervical cancer screening test among female health workers in a tertiary health institution. Int J Gynecol Cancer 16: 1063-1068.

2. World Health organisation (2002) Cervical cancer screening in developing countries. Report of a WHO consultation, Geneva.

3. (2004) UNDP/UNFPA/WHO/World Bank Special Programme of Research. Development and Research Training in Human Reproduction (HRP).

4. National cervical cancer coalition. Cervical cancer screening saves lives.

5. Wright KO, Kuyinu YA, Fadiyile FA (2010) Community education on cervical cancer amongst market women in an urban area of Lagos, Nigeria. Asian Pacific J Cancer Prev 10: 137-140.

6. Emembolu JO, Ekwempu CC (1988) Carcinoma of the cervix uteri in zaria. Aetological factors Int J. Gynaecol Obstet 26: 265-269.

7. Ijaiya MA, Aboyeji PA, Buhari MO (2004) Cancer of the cervix in Ilorin, Nigeria. West Afri J Med 23: 319-322.

8. Olu-Eddo AN, Ekanem VJ, Umannah I, Onakarhor J (2011) A 20 year clinicopathologic review of cancer of the cervix in Nigeria. Nig Q J Med 21: 149-153.

9. Ozoigwe GO, Seleye-Finbarr D (2004) Cancer of the uterine cervix in Port-Harcourt, rivers state-a 13 year clinicopathological review. Niger J Med 13: 110-113.

10. Awodele O, Adeyomoye AAA, Awodele DF, Kwashi V, Awodele IO, Dolapo DC (2011) A Study on Cervical Cancer Screening Amongst Nurses in Lagos University Teaching Hospital, Lagos, Nigeria. J Canc Educ 26: 497-504.

11. An update on the Papanicolaou test.

12. Louie SK, de Sanjose S, Mayaud P (2009) Epidemiology and prevention of Human Papilloma Virus and cervical cancer in Sub Saharan Africa: a comprehensive review. Tropical medicine and international Health 14: 1287-1302.
13. American cancer society (2007) Cancer prevention and early detection: Facts and figures. American cancer society, Atlanta GA.

14. Cancer Research UK (2007) Cervical cancer screening in the UK.

15. Audu BM, El-Nafaty AU, Khalil M, Otubu JAM (1999) Knowledge and attitude of cervical cancer screening among women in Maiduguri. J Obstet Gynaecol 19: 295-297.

16. Centers for disease control and prevention (2016) Behavioural risk factor surveillance system. National center for chronic disease and prevention and health promotion, Atlanta GA.

17. Ezem BU (2007) Awareness and uptake of cervical cancer screening in Owerri, South-Eastern Nigeria. Ann Afr Med 6: 94-98.

18. Dim CC, Ekwe E, Madubuko T, Dim NR, Ezegwui HU (2009) Improved awareness of Pap smear may not affect its use in Nigeria: a case study of female medical practitioners in Enugu, southeastern Nigeria, Royal Society of Tropical Medicine and Hygiene 103: 852-854.

19. Ayinde OA, Omigbodun AO (2003) Knowledge, attitude and practices related to prevention of cancer of the cervix among female health workers in Ibadan. J Obstet Gynaecol 23: 59-62.

20. Mutyaba T, Mmiro FA, Weiderpass E (2006) Knowledge, attitudes and practices on cervical cancer screening among the medical workers of Mulago Hospital, Uganda. BMC Medical Education 6: 13.

21. Urasa M, Darj E (2011) Knowledge of cervical cancer and screening practices of nurses at a regional hospital in Tanzania, African Health Sciences 11: 48-57.

22. Nganwai P, Truadpon P, Inpa C, Sangpetngam B, Mekjarasnapa M, et al. (2008) Knowledge, Attitudes and Practices vis-à-vis Cervical Cancer among Registered Nurses at the Faculty of Medicine, Khon Kaen University, Thailand. Asian Pac J Cancer Prev 9: 15-18.

23. Lartey M, Joubert G, Cronje HS (2003) Knowledge, attitudes and practices of rural women in South Africa regarding the Pap smear. Int J Gynaecol Obstet 83: 315-316.

24. Nkyekyer K (2000) Pattern of gynaecological cancers in Ghana. East Afr Med J 77: 534-538. 